\title{
Análisis comparativo del estado de los ecosistemas de manglar entre los municipios de la costa pacífica chocoana
}

\section{Comparative analysis of the state of the ecosystems of mangrove swamp between the municipalities of pacific coast Chocoana}

\author{
William Klinger Brahan', Neiver Obando Mosquera
}

\section{RESUMEN}

Los manglares se destacan por su alta productividad y producción de materia orgánica, promueven la biodiversidad porque sus raíces sumergidas proveen habitáculo y refugio para una rica fauna de peces, mamíferos e invertebrados. No obstante muchos de ellos han sido destruidos o están en peligro de desaparecer. Con el objetivo de analizar comparativamente la situación actual de los ecosistemas de manglar en los cinco municipios costeros del pacífico chocoano, el IIAP desarrolló este estudio, utilizando una metodología que permitiera realizar este análisis en relación con las coberturas de estos ecosistemas y los niveles de intervención que presentan. Se encontró que el municipio del Bajo Baudó aporta al departamento del Chocó más de la mitad de los manglares + natales y Bahía Solano tiene más del $82 \%$ de sus manglares en alta condición de deterioro. De igual manera se encontró que el municipio de Nuquí alcanza un $60 \%$ del ecosistema altamente intervenido. La intervención de los natales se presenta en menor proporción a pesar de la buena calidad de su madera. En conclusión es muy poca la superficie de manglares que presenta bajos niveles de intervención lo que hace imperioso el desarrollo de acciones dirigidas a salvar el ecosistema, dada su mundialmente reconocida importancia económica y ecológica.

Palabras clave: Manglar; Natal; Intervención; Cobertura.
1. Ingeniero Forestal, MSc. Profesor Titular de la Universidad Distrital Francisco José de Caldas, Facultad de Medio Ambiente y Recursos Naturales, Grupo de Investigación PROPOBOS y Director del Instituto de Investigaciones Ambientales del Pacífico (IIAP), Quibdó, Colombia. e-mail: wklinger@iiap.org.co

2. Ingeniero Agroforestal, Profesional de Áreas protegidas, Corporación Autónoma para el Desarrollo Sostenible del Chocó (COEDECHOCÓ), Quibdó, Colombia. e-mail: nomos1979@gmail.com Recibido: Junio 26, 2009 Aceptado: Julio 10, 2009

\begin{abstract}
The mangrove swamps stand out by their high productivity and production of organic matter, promote the biodiversity since their submerged roots provide cockpit and refuge for a rich fauna with fish, mammals and invertebrates. Despite many of them they have been destroyed or they are in danger to disappear. With the aim of analyzing comparativily, the present situation of the ecosystems of mangrove swamp in the five coastal municipalities of the chocoano Pacific, the IIAP development this study, being used a methodology that allowed to realise this in analysis in relation to the covers of these ecosystems and the levels of intervention that present/display. One was that the municipality of the Low Baudó contributes to the department of Chocó more than half of mangrove swamps + birthdays and Bahia Solano has more of $82 \%$ of its mangrove swamps in high condition of deterioration. Of equal way one was that the municipality of Nuqui reaches a $60 \%$ of the ecosystem highly taken part. The intervention of the birthdays appears in smaller proportion in spite of the good quality of its wood. In conclusion the surface of mangrove swamps is very little that presents/displays low levels of intervention which makes the development urgent of directed actions save the ecosystem, given his world-
\end{abstract}


wide recognized economic and ecological importance.

Keyword: Mangrove swamp; Birthday; Intervention; Cover.

\section{INTRODUCCIÓN}

Muchos especialistas han considerado el manglar como el ecosistema de más alta productividad en el mundo. Según Odum y De la Cruz (1967), aproximadamente dos tercios de las poblaciones de peces en el mundo dependen de las áreas de manglar. Es reciclador de $\mathrm{CO}_{2}$ y fuente de materia orgánica e inorgánica, así como un excelente detoxificador y amortiguador de inundaciones (Sánchez y Álvarez 1997). Lo anterior muestra la importancia del ecosistema de manglar y la urgente necesidad de conocer su situación actual para procurar decisiones que apunten a su conservación en buen estado y así aprovechar sus innumerables ventajas, de allí la preocupación de Corporación Autónoma para el Desarrollo Sostenible del Chocó (COEDECHOCO) y del Instituto de Investigaciones Ambientales del Pacífico (IIAP) por poner a la disposición del público una información de tan reconocida valía.

En este artículo se hace una mirada comparativa en cuanto a la existencia y grado de intervención del ecosistema de manglar de los municipios chocoanos ubicados en la costa pacífica, Juradó, Bahía Solano, Nuquí, Bajo Baudó y Litoral del San Juan. El análisis integra, pero al mismo tiempo muestra por separado, la situación de los natales y de los manglares propiamente dichos, así como también separa los diferentes grados de intervención para luego darles una mirada conjunta.

El objetivo general es analizar comparativamente, la situación actual de los ecosistemas de manglar en los cinco (5) municipios costeros del pacífico chocoano, Juradó, Bahía Solano, Nuquí, Bajo Baudó y Litoral del San Juan.

Como objetivos específicos se comparará el estado actual de los manglares en los municipios de la costa pacífica del departamento del Chocó, en lo que hace relación a su cobertura espacial y la relación con los niveles de intervención que estos presentan.

\section{METODOLOGÍA}

Área de estudio. El presente estudio abarca todas las áreas de manglar presentes en los municipios de la costa chocoana Juradó, Bahía Solano, Nuquí, Bajo Baudó y Litoral del San Juan, cuyas características ambientales y biológicas son similares en algunos aspectos y particulares en otros. En la costa del Pacífico los manglares se presentan como una faja paralela al litoral, la cual en algunas partes penetra hacia el continente $20 \mathrm{~km}$ o más con influencia de la marea. Esta faja va desde el sur en la frontera con Ecuador y se remonta hasta
Cabo Corrientes, se sucede en algunas manchas hasta llegar a los límites con la República de Panamá. Las áreas de manglar se encuentran de norte a sur, en Juradó, en la Encenada de Utría, reaparecen en Nuquí, hacia el sur de Cabo Corrientes aparecen los manglares de Virudó-Catripe, los de la desembocadura del río Baudó y el río San Juan, siguiendo hacia el sur reaparecen en las Bahías de Málaga y Buenaventura (Villalba, 2008). Estos municipios como la mayoría de los del Pacífico, poseen una de las precipitaciones más altas del planeta y las mareas oscilan en un rango aproximadamente de cuatro metros, cuyas características entre otras hacen que los mangles del litoral Pacífico alcancen los $40 \mathrm{~m}$ de altura, donde las principales especies son Pelliciera rhizophorae y Mora megistosperma en áreas extensas denominadas natales (Phral 1989).

En cuanto a la fauna, en esta área del Pacífico sobre los troncos bañados por las mareas se incrustan algas que son alimento de moluscos durante la marea baja al igual que el cangrejo tasquero Goniopsis cruentata; en las raíces se encuentra la ostra Crassostrea rhizophorae que es el habitante típico, a su vez el caracol Thais kiosquiformis preda las ostras y los cirripeditos Balanus sp; también se destacan otras especies comoTeredo novilis, Ophiotrix, Anadaraspp, Penaeus spp, Alpheus spp, Xiphopenaeus kroyeri $y$ Anamalocardia sp entre otras. Asimismo se encuentran especiesícticas asociadas con el manglar comoróbalo, mojarra, lebrance, lisa, sábalo, barbudo, pargo, barracuda y corbinata entre otras (Sánchez et al. 2004).

Métodos. La metodología para realizar la caracterización y zonificación de los manglares del Pacífico chocoano, se dividió en dos partes, la primera de análisis de las imágenes digitales para manglar, la delineación y actualización de la línea costera y el trabajo de campo concerniente a la validación y verificación del estado del manglar de la zona de estudio. Se establecieron siete zonas de muestreo distribuidas en 64.780 ha que corresponde a las áreas de manglar de los cinco municipio ubicados en la costa del departamento (Sánchez et al. 1997), Jurado, Bahía Solano, Nuquí, Bajo Baudó y Litoral del San Juan, teniendo como base el área de manglar de cada uno.

Se tuvo en cuenta además de lo contemplado en la Resolución 0721/2002 para la determinación de la cobertura vegetal y la zonificación del ecosistema, las teorías de Lamprecht (1990), con respecto a la organización florística [según Lamprech, el bosque es una conformación vegetal que ocupa tres dimensiones. Por lo tanto hay que incluir en toda investigación el estudio de la expresión vertical boscosa, para este fin propone el análisis de la llamada «estructura sociológica» cuyo primer paso es la definición de una estructura vertical) y los aportes y consideraciones de Agudelo con respecto a los métodos de muestreo (el muestreo al azar simple con fajas, es uno de los mejores métodos para 


\section{Bioetnia Volumen 6 № 2 (julio-diciembre), 2009}

muestrear, esto debido a que la longitud de la faja supera cientos de veces su ancho lo cual representa su máxima ventaja en la relación óptima que se establece entre tiempos de marcha y área barrida al inventariar, sobre todo en bosques tropicales en donde se acepta como probada su eficiencia] (Agudelo 2002) y los criterios que se relacionan a continuación:

- Intensidad de muestreo de $0.7 \%$ con un error de muestreo inferior a $25 \%$.

- El muestro se realizó con el sistema de fajas al azar de forma rectangular, con un ancho de 10 metros por el sistema de cuadrante.

- Se inventariaron todos los árboles con diámetro mayor o igual a $15 \mathrm{~cm}$ y altura mayor o igual a $3 \mathrm{~m}$ para la regeneración fustal, latizal con diámetro entre 5 y $15 \mathrm{~cm}$ y altura entre 1.5 y $3 \mathrm{~m}$.

Se estructuraron subparcelas para la medición de brinzales (diámetro entre $2.5-5 \mathrm{~cm}$ y altura menor o igual a $1.5 \mathrm{~m}$ ). Para el logro de los objetivos del presente estudio, se planteó la utilización de una metodología analítica y descriptiva, la cual fue utilizada por Sánchez y Álvarez (1997) en desarrollo del proyecto «Diagnóstico y zonificación preliminar de los manglares del Pacífico de Colombia», avalada por la OIMT, ACOFORE y el MMA; posteriormente aplicada con las modificaciones referenciadas en la Resolución 233 de 1999 del Ministerio del Medio Ambiente por CORPOURABA, mediante el proyecto «Zonificación y ordenamiento de los manglares de Urabá, Antioquia», Convenio 201671 FONADECORPOURABA y descrita en la Resolución 0721 del 31 de julio de 2002.

Análisis de las imágenes digitales para manglar, la delineación y actualización de la línea costera. El presente documento se elabora con información de imágenes de satélite corroborada con un intenso trabajo de campo concluido en el año 2005, con él se pretende la fácil ubicación del ecosistema de manglar, conocer el estado actual del deterioro del ecosistema, establecer una zonificación preliminar y tener claras orientaciones de manejo, para que la autoridad ambiental tome decisiones inmediatas frente a los problemas encontrados.

Se utilizaron 8 imágenes multiespectrales de diferentes fechas de toma del satélite LANDSAT TM y ETM+, que abarcan la zona costera del Pacífico del departamento del Chocó, aunque para la generación de polígonos se procesaron sólo cuatro imágenes de las fechas más recientes (2001, 2000, 1999 y 1997), una imagen Radarsat y cartografía base de planchas IGAC. Para manejar la información digital de las imágenes y ligarlas al sistema coordenado IGAC se deben corregir los errores por geometría de la imagen, especialmente radar. Se dispuso a geo-rectificar las imágenes utilizando para ello la cartografía digital disponible de la zona del Pacífico a escala 1:25.000, como imágenes mosaico de la NASA con resolución de $15 \mathrm{~m}$ y especialmente puntos de control toma- dos con la unidad de GPS Garmin en sitios claves que no estuvieran sujetos a dinamismo temporal.

Fase de campo. En esta etapa se realizaron dos visitas de campo, la primera en la zona costera de los municipios de Juradó, Bahía Solano y Nuquí y la segunda a los municipios de Bajo Baudó y Litoral San Juan. Las visitas fueron esenciales para identificar los hábitats de manglar presentes en el área de estudio, registrar su localización, reconocer las otras coberturas vegetales que comparten la misma unidad paisajística y de relieve y tomar puntos de control para rectificar las imágenes de satélite. Estos aspectos fueron muy útiles en el momento de realizar la clasificación de las imágenes satelitales, permitiendo obtener referencias independientes de datos que ayudaron a evaluar la precisión de los resultados obtenidos después del procesamiento digital de las imágenes satelitales.

Las visitas realizadas a la zona costera del Pacífico del departamento del Chocó, se hicieron con el objeto de crear un dependencia con el área de estudio y una familiarización con la zona, como también hacer comprobación en las parcelas de muestreo, realizadas meses anteriores por el grupo de ingenieros forestales contratistas del IIAP (primera fase proyecto manglares). Además, fue de suma importancia la recolección de información para calibrar las imágenes satelitales que cubren el área de estudio.

\section{RESULTADOS Y DISCUSIÓN}

Sobre las coberturas de manglares y natales. En la Tabla 1 se muestra la superficie total cubierta por mangles y natos por municipios de la costa pacífica del departamento del Chocó, así como la distribución porcentual de estas coberturas por municipio, hecho que facilita la comprensión del análisis comparativo de estos datos y muestra la situación de mayor o menor disponibilidad de recursos asociados con estos ecosistemas en cada uno de los entes territoriales objeto del presente estudio.

El municipio del Bajo Baudó aporta al departamento del Chocó más de la mitad de los manglares + natales ubicados en su costa pacífica, lo que supone una situación estratégica de este municipio. Por su parte, el Litoral del San Juan aporta más de la cuarta parte en superficie al ecosistema de manglar del pacífico chocoano, hecho que también abre las compuertas para hacer una mirada en procura de desarrollar un trabajo orientado a garantizar la permanencia del ecosistema en este municipio.

El aporte de área de manglar que hacen los municipios ubicados en el centro y norte de la costa pacífica chocoana, Nuquí, Bahía Solano y Juradó, aunque importante, es incipiente si se le compara con los municipios del sur, que acaparan entre ellos más del $84 \%$ del ecosistema de manglar, lo que muestra una clara tendencia de disminución del ecosistema a medida que se desplaza hacia el norte siguiendo 
Tabla 1

Existencia de manglares + natales en la costa pacífica del Chocó

\begin{tabular}{lcc}
\hline Municipio & Superficieen manglares + natales (ha) & $\begin{array}{c}\text { Porcentaje de la superficie total en } \\
\text { manglares + natales en el Chocó }\end{array}$ \\
\hline Juradó & 2.237 .1 & 5.4 \\
\hline Bahía Solano & 1.070 .0 & 2.6 \\
\hline Nuquí & 3.022 .4 & 7.3 \\
\hline Bajo Baudó & 23.923 .4 & 57.9 \\
\hline Litoral del San Juan & 11.063 .0 & 26.8 \\
\hline Total & 41.315 .9 & 100.0 \\
\hline
\end{tabular}

Tabla 2

Manglares + natales con altos niveles de intervención por municipios de la costa pacífica chocoana

\begin{tabular}{cccc}
\hline Municipio & $\begin{array}{c}\text { Manglares y natales } \\
\text { altamente intervenidos } \\
\text { (ha) }\end{array}$ & $\begin{array}{c}\% \text { del total de manglares + natales } \\
\text { altamente intervenidos }\end{array}$ & $\begin{array}{c}\% \text { del área municipal } \\
\text { en manglares + natales }\end{array}$ \\
\hline
\end{tabular}

\begin{tabular}{lrrr}
\hline Juradó & 1.056 .2 & 6.1 & 47.2 \\
Bahía Solano & 885.4 & 5.1 & 82.7 \\
Nuquí & 1.799 .1 & 10.3 & 59.5 \\
Bajo Baudó & 8.039 .8 & 46.2 & 33.6 \\
Litoral del San Juan & 5.628 .3 & 32.3 & 50.9 \\
Total & 17.408 .8 & 100.0 & \\
\hline
\end{tabular}

la franja occidental.

Sobre los niveles de intervención de manglares y natales. En la Tabla 2 se presentan los datos relacionados con los niveles de intervención que presentan los manglares y natales en la costa pacífica chocoana, discriminados por municipio, con el objeto de no generar confusiones desde el análisis de la información; la tercera columna muestra la participación de cada municipio en el total del ecosistema de manglar altamente intervenido, que no es igual al porcentaje que representa la superficie altamente intervenida del total de superficie de manglar de cada municipio, lo que se muestra en la última columna hacia la derecha.

Como es de esperarse, por la baja presencia de ecosistema de manglar en los municipios de Nuquí, Juradó y Bahía Solano, su contribución al mapa de los altamente intervenidos también es baja, sin embargo, obsérvese que mientras en existencia estos tres municipios representan $15.3 \%$ de la superficie total en manglares, en cuanto a manglares altamente intervenidos el porcentaje sube a $21.5 \%$, lo que se explica por el alto número de manglares altamente intervenidos que tienen Bahía Solano y Nuquí en relación con el resto de los municipios, hecho que seguramente está en función de los mayores desarrollos de infraestructura que estos tienen.

Haciendo referencia al dato de porcentaje absoluto de cada municipio en manglares altamente intervenidos, preocupa enormemente la situación de Bahía Solano que tiene más de $82 \%$ de sus manglares en alta condición de deterioro. De igual manera preocupa la situación del municipio de Nuquí que tiene mayores existencias de manglar que Bahía Solano y alcanza prácticamente $60 \%$ del ecosistema altamente intervenido, lo que en valores absolutos significa casi el doble de hectáreas más que su vecino, calificadas en alto grado de intervención.

Aunque el Bajo Baudó presenta el más bajo porcentaje de sus ecosistemas de manglares con altos grados de intervención $(33.6 \%)$ por el tamaño tan relativamente grande de su superficie en manglares, su aporte al grupo de los altamente intervenidos es de más de 8.000 hectáreas. En este mismo sentido parece más preocupante la situación del municipio del Litoral del San Juan, en el que los avances del deterioro de sus manglares va a ritmos más altos que en el Bajo Baudó, porque su superficie de manglares en alta intervención es de 50.9\%, 
Bioetnia Volumen 6 No 2 (julio-diciembre), 2009

Tabla 3

Manglares + natales medianamente intervenidos por municipios de la costa pacífica chocoana

\begin{tabular}{lccc}
\hline Municipio & $\begin{array}{c}\text { Manglares + natales } \\
\text { medianamente intervenidos }\end{array}$ & $\begin{array}{c}\text { \% del total de manglares + natales } \\
(\mathbf{h a}) \text { medianamente intervenidos }\end{array}$ & $\begin{array}{c}\text { del área municipal en } \\
\text { manglares + natales }\end{array}$ \\
\hline Juradó & 602.8 & 3.7 & 27.0 \\
Bahía Solano & 99.5 & 0.6 & 9.3 \\
Nuquí & 506.9 & 3.1 & 16.8 \\
Bajo Baudó & 12.737 .7 & 77.2 & 53.2 \\
Litoral del San Juan & 2.558 .2 & 15.5 & 23.1 \\
Total & 16.505 .1 & 100.0 & \\
\hline
\end{tabular}

Tabla 4

Superficie de manglar + natal poco intervenido por municipios de la costa pacífica chocoana

$\begin{array}{cccc}\text { Municipio } & \begin{array}{c}\text { Manglares + natales } \\ \text { poco intervenidos }\end{array} & \begin{array}{c}\% \text { del total de manglares + natales } \\ \text { (ha) poco intervenidos }\end{array} & \begin{array}{c}\% \text { dea municipal en } \\ \text { manglares + natales }\end{array}\end{array}$

\begin{tabular}{lccc}
\hline Juradó & 578.1 & 7.8 & 25.8 \\
Bahía Solano & 85.1 & 1.2 & 8.0 \\
\hline Nuquí & 716.4 & 9.7 & 23.7 \\
Bajo Baudó & 3.145 .9 & 42.5 & 13.1 \\
Litoral del San Juan & 2.876 .5 & 38.9 & 26.0 \\
Total & 7.402 & 100.0 & \\
\hline
\end{tabular}

es decir, si la superficie de este ecosistema en el Litoral del San Juan fuese del mismo tamaño que en el Bajo Baudó, estarían en grado de alta intervención 12.177 hectáreas.

La situación de Juradó no deja de causar preocupación, a pesar de tener un porcentaje de manglares en niveles de alta intervención de $47.2 \%$ y representar desde esta mirada el segundo de los municipios con mejores resultados en la protección de sus manglares; tener casi la mitad de su ecosistema de manglar en grado alto de intervención enciende las alarmas, máxime cuando se trata de un municipio donde hay bajas existencias de manglar en términos generales.

Si al análisis anterior se le adiciona la categoría de los manglares medianamente intervenidos, se hace mucho más palpable la condición de deterioro que presentan estos ecosistemas en el pacífico chocoano. En la Tabla 3 se presenta el resumen de datos correspondiente a los manglares en esta situación.

Nótese por ejemplo que para el caso del municipio de Juradó, si se sumara el porcentaje de manglares altamente intervenidos al porcentaje de los manglares medianamente intervenidos, el dato resultaría en más del 74\%, lo que hace suponer que sólo queda $26 \%$ de los manglares de este municipio en buen estado.
Asimismo, si a las superficies de manglares altamente intervenidas se les suma la superficie de los medianamente intervenidos, se encienden luces de alerta para el municipio de Bajo Baudó, que teniendo el menor porcentaje en manglares en alta intervención, llegaría a $86.8 \%$ integrando los manglares con intervenciones medias y altas, lo cual deja sin piso cualquier opción de mostrarlo como el municipio modelo en protección del manglar.

Aunque el porcentaje manglares medianamente intervenidos en Bahía Solano es bajo, la suma con los altamente intervenidos resulta en un agobiante $92 \%$, es decir, al momento sólo queda $8 \%$ de manglares en buen estado en jurisdicción de este importante ente territorial, que debería utilizar el ecosistema para introducir variables de turismo ecológico que hagan más compatible la actividad turística con la situación de sus recursos naturales.

Desde esta misma perspectiva, los municipios de Litoral del San Juan y Nuquí superarían 74\% al integrar manglares altamente y medianamente intervenidos, situación que en conjunto muestra el oscuro panorama de los manglares del Chocó, específicamente los que se encuentran ubicados en el Andén Pacífico.

En la Tabla 4 se presenta el porcentaje de manglares en 
Estado de los ecosistemas de manglar. W Klinger, N Obando

Tabla 5

Situación de los natales por municipios de la costa pacífica chocoana

\begin{tabular}{lccc}
\hline Municipio & $\begin{array}{c}\text { Manglares } \\
\text { altamente intervenidos (ha) }\end{array}$ & $\begin{array}{c}\text { \% del total de manglares } \\
\text { poco intervenidos (ha) }\end{array}$ & $\begin{array}{c}\text { Superficie total de } \\
\text { natales (ha) }\end{array}$ \\
\hline Juradó & 0.0 & 140.0 & 140.0 \\
Bahía Solano & 232.3 & 0.0 & 232.3 \\
Nuquí & 100.3 & 411.7 & 512.0 \\
Bajo Baudó & 278.1 & 1.468 .2 & 1.746 .3 \\
Litoral del San Juan & 826.4 & 1.921 .5 & 2.747 .9 \\
Total & 1.437 .1 & 3.941 .4 & 5.378 .5 \\
\hline
\end{tabular}

buen estado de conservación o poco intervenido por cada uno de los municipios que conforman el litoral pacífico chocoano, es un anuncio claro de lo que nos queda en una condición que de asegurársele un adecuado manejo, podría garantizar la existencia de este importante ecosistema.

Los datos hablan por sí solos, ninguno de los municipios de la costa pacífica chocoana cuenta con más de $26 \%$ de su ecosistema de manglar en adecuadas condiciones de conservación. Se registran como alarmantes los casos de Bahía Solano y Bajo Baudó, que tienen tan solo, respectivamente, el $7.95 \%$ y $13.14 \%$ de sus manglares en condición de poco intervenidos. Se registran como preocupantes los casos Nuquí, Juradó y Litoral del San Juan, los cuales presentan datos muy similares en cuanto a manglares bien conservados.

Cuando se observa específicamente la situación del Nato (Mora megistosperma), en general el panorama es menos preocupante e inclusive aparecen excelentes datos en algunos municipios, pero en particular se encuentran situaciones como la de Bahía Solano, que urge de atención inmediata. En esta municipalidad el $100 \%$ del Natal existente se encuentra en niveles de alta intervención, es decir, de continuar el ritmo de su utilización poco racional, el ecosistema tendería a desaparecer (Tabla 4).

La Tabla 5 muestran lo que ocurre con el natal en la costa pacífica chocoana, por ejemplo, $100 \%$ de los natales del municipio de Juradó se encuentra en niveles de poca o baja intervención, que en el municipio del Bajo Baudó los natales bien conservados corresponden al $84 \%$ y que los natales del municipio del Litoral del San Juan calificados como poco intervenidos representan $69.9 \%$ del total de sus natales.

\section{LA SITUACIÓN GENERAL DE LOS MANGLARES EN LA COSTA PACÍFICA DEL DEPARTAMENTO DEL CHOCÓ}

En su costa pacífica, el departamento del Chocó posee un total de 41.315.9 hectáreas en manglares; esta superficie es aportada en mayor cantidad por el municipio del Bajo Baudó en donde se ubican 23.923.4 hectáreas, que corresponden a $57.9 \%$ del total de manglares encontrados en la subregión. En segundo lugar en cuanto aportes a la superficie total de manglares se encuentra el municipio del Litoral del San Juan con 11.063 hectáreas que corresponden al $26.78 \%$.

Los municipios de Bahía Solano, Juradó y Nuquí aportan entre todos una superficie de manglares incipiente, que sumada no alcanza el $15.4 \%$ del área total en manglares que tiene la costa pacífica del departamento del Chocó. La Tabla 6 muestra un consolidado de la existencia de manglares en la subregión del pacífico chocoano, de igual manera las gráficas que se presentan a continuación.

La comparación de estos datos que corresponden al año 2005, con los reportados por Sánchez (1997), prende las alertas y deja ver a las claras una situación absolutamente preocupante, se concluye que en escasos 9 años, se ha pasado de tener 64.750.4 hectáreas a 41.315.9 hectáreas, lo que arroja una pérdida 23.434.5 hectáreas, es decir, 2.603.8 ha/año, lo cual indica que de continuar a este ritmo de intervención, hacia el año 2021, la costa pacífica del departamento del Chocó no tendría manglares, con todos los impactos que ello implica, tanto para asuntos ecológicos, como para temas de producción de alimentos.

Adicionalmente, el ecosistema de manglar de la costa pacífica chocoana presenta en general altos niveles de intervención que obligan a tener consideraciones especiales en la búsqueda de su recuperación o lo que es más urgente aun, en ponerle freno al uso irracional de las especies de un ecosistema tan importante.

La Tabla 7 muestra en conjunto los datos correspondientes a los niveles de intervención de los manglares propiamente dichos, en ella se observa que de las 35.937.4 hectáreas que en total existen en la costa pacífica del departamento del Chocó, tan solo 3.460.6 se encuentran en bajo grado de intervención, lo que significa que únicamente $9.6 \%$ de la superficie total de manglares propiamente dichos que tiene la 


\section{Bioetnia Volumen 6 No 2 (julio-diciembre), 2009}

Tabla 6

Existencia de bosque de manglar en el pacífico chocoano

\begin{tabular}{lcc}
\hline Municipio & $\begin{array}{c}\text { Superficie en } \\
\text { manglares (ha) }\end{array}$ & \% \\
\hline Bajo Baudó & 23.923 .4 & 57.9 \\
Litoral del San Juan & 11.063 .0 & 26.8 \\
Nuquí & 3.022 .4 & 7.3 \\
Juradó & 2.237 .1 & 5.4 \\
Bahía Solano & 1.070 .0 & 2.6 \\
\hline Total & 41.315 .9 & 100 \\
\hline
\end{tabular}

especies que conforman los manglares, el panorama es menos sombrío, lo que no coincide con el reconocimiento que tiene la madera de nato como una especie de excelente calidad estructural. La costa pacífica del Chocó tiene un total de 5.378.5 hectáreas de natales, de los cuales 1.437.1 hectáreas se encuentran altamente intervenidas y 3.941.4 hectáreas se encuentran poco intervenidas. La Tabla 8 muestra el resumen de los datos correspondientes a natales, de su lectura se deduce que $73 \%$ de los natales de la costa pacífica chocoana se encuentran en un estado adecuado de conservación, mientras que el restante $27 \%$ se encuentra altamente intervenido.

En los natales se presentan condiciones extremas; si se hace un análisis de sus niveles de intervención, la comunidad los interviene de manera intensiva o definitivamente no se

Tabla 7

Grado de intervención de los manglares en la costa pacífica chocoana

\begin{tabular}{lcccc}
\hline \multirow{2}{*}{ Municipio } & \multicolumn{3}{c}{ Manglares intervenidos (ha) } & \multirow{2}{*}{$\begin{array}{c}\text { Superficie total de } \\
\text { manglares (ha) }\end{array}$} \\
\cline { 2 - 4 } & altamente & medianamente & poco & \\
\hline Juradó & 1.056 .2 & 602.8 & 438.1 & 2.097 .1 \\
\hline Bahía Solano & 653.1 & 99.5 & 85.1 & 837.7 \\
\hline Nuquí & 1.698 .8 & 506.9 & 304.7 & 2.510 .4 \\
\hline Bajo Baudó & 7.761 .7 & 12.737 .7 & 1.677 .7 & 22.177 .1 \\
Litoral del San Juan & 4.801 .9 & 2.558 .2 & 955.0 & 8.315 .1 \\
\hline Total & 15.971 .7 & 16.505 .1 & 3.460 .6 & 35.937 .4 \\
\hline
\end{tabular}

costa pacífica chocoana se encuentran adecuadamente conservados.

Se deduce también de esta información, que $44.4 \%$ de los manglares propiamente dichos que tiene el departamento del Chocó en su costa pacífica, presenta altos niveles de intervención, lo cual corresponde a casi 16.000 hectáreas y obliga a tomar medidas inmediatas para impedir que se siga deteriorando el ecosistema de manglar. Otras 16.505.1 hectáreas que representan $45.9 \%$ del total de ecosistema de manglar en la costa pacífica del Chocó presenta niveles medios de intervención, lo que oscurece mucho más el panorama general sobre el estado actual del manglar.

En realidad es muy poca la superficie de manglares que presenta bajos niveles de intervención en el pacífico chocoano; del total de las 41.315.9 hectáreas de manglares de esta subregión, tan sólo 7.402 hectáreas se encuentran poco intervenidas, lo que arroja apenas un aproximado $18 \%$ de manglares conservados. Esta información hace imperioso el desarrollo de acciones dirigidas a salvar el ecosistema, por su mundialmente reconocida importancia económica y ecológica.

Si se observan los natales con independencia de las otras mete con ellos, al menos no de forma significativa. Durante el desarrollo del trabajo no se encontraron natales medianamente intervenidos, razón por la que no se tiene en los mapas y documentos esta categoría de intervención.

Si se analizan conjuntamente manglares propiamente dichos y natales, $41.8 \%$ del ecosistema de manglar presenta altos niveles de intervención antrópica, $39.9 \%$ tiene niveles medianos de intervención y tan sólo $18.3 \%$ se encuentra poco intervenido como se observa en la Tabla 9.

\section{LITERATURA CITADA}

Odum, E. P., A. A. De La Cruz. 1967. Particulate organic detritus in a Georgia salt marsh-estuarine ecosystem. p. Zn G. H. Lauff [cd.], Estuaries. Am Assoc Adv Sci Pub. 83: 383-88.

Sánchez-Páez, H., Alvarez-León, R., Pinto-Nolla, F., Sánchez-Alferez, A.S., Pino-Renjifo, J.C., Acosta- Peñaloza, M. T. et al. 1997a. Diagnóstico y zonificación preliminar de los manglares del Caribe de Colombia. Proy. PD 171/91. Rev 2 (F). Fase I. Bogotá, DC: MinAmbiente/OIMT.343 p.

Ministerio de Ambiente, Vivienda y Desarrollo Territorial. 2002. Resolución 0721 de 2002. Bogotá,DC.

Lamprecht, H. 1990. Silvicultura en los trópicos. Los ecosistemas forestales en los bosques tropicales y sus especies arbóreas. Posibilidades y métodos 
Estado de los ecosistemas de manglar. W Klinger, N Obando

Tabla 8

Grado de intervención de los natales en la costa pacífica chocoana

\begin{tabular}{lccc}
\hline Municipio & \multicolumn{2}{c}{ Natales } & Superficie total de natales (ha) \\
\cline { 2 - 3 } & altamente intervenidos (ha) & poco intervenidos (ha) & \\
\hline Juradó & 0.0 & 140.0 & 140.0 \\
Bahía Solano & 232.3 & 0.0 & 232.3 \\
Nuquí & 100.3 & 411.7 & 512.0 \\
Bajo Baudó & 278.1 & 1.468 .2 & 1.746 .3 \\
Litoral del San Juan & 826.4 & 1.921 .5 & 2.747 .9 \\
Total & 1.437 .1 & 3.941 .4 & 5.378 .5 \\
\hline
\end{tabular}

Tabla 9

Grado de intervención de manglares y natales en la costa pacífica chocoana

\begin{tabular}{|c|c|c|c|c|}
\hline \multirow[t]{2}{*}{ Municipio } & \multicolumn{3}{|c|}{ Manglares y natales intervenidos (ha) } & \multirow{2}{*}{$\begin{array}{c}\text { Superficie total de manglares } \\
\text { y natales (ha) }\end{array}$} \\
\hline & altamente & medianamente & poco & \\
\hline Juradó & 1.056 .2 & 602.8 & 578.1 & 2.237 .1 \\
\hline Bahía Solano & 885.4 & 99.5 & 85.1 & 1.070 .0 \\
\hline Nuquí & 1.799 .1 & 506.9 & 716.4 & 3.022 .4 \\
\hline Bajo Baudó & 8.039 .8 & 12.737.7 & 3.145 .9 & 23.923 .4 \\
\hline Litoral del San Juan & 5.628 .3 & 2.558 .2 & 2.876 .5 & 11.063 .0 \\
\hline Total & 17.408 .8 & 16.505 .1 & 3.460 .6 & 41.315 .9 \\
\hline
\end{tabular}

para un aprovechamiento sostenido. Deutsche Gesellschaft für Technische Zusammenar beit (GTZ) Cooperación Técnica-República Federal de Alemania. Eschborn; p. 276-88.

Agudelo-Valderrama, A. 2002. Silvicultura y agrometeorología. Informe final. Caldas: Centro Agropecuario La Salada; .2002.

Ministerio del Medio Ambiente. 1999. Resolución $N^{\circ} 233$ de 1999. Bogotá, DC: Ministerio del Medio Ambiente.

CORPOURABA. 2002. Zonificación y ordenamiento de los manglares del Golfo Urabá, Departamento de Antioquia. Convenio 201671. Apartadó: FONADECORPOURABA; $310 \mathrm{pp}$.

Prahl, H. Von, Cantera, J. R., Contreras R. 1990. Manglares y hombres del
Pacífico colombiano. Bogotá, DC: Fondo FEN-COLCIENCIAS.

Sánchez-Páez, H. Ulloa-Delgado, G. A., Tavera- Escobar, H. V. 2004. Manejo Integral de los manglares por comunidades locales, Caribe de Colombia. Proyecto Manejo Sostenible y Restauración de los Manglares por comunidades locales del Caribe de Colombia. Bogotá, DC: Ministerio de Ambiente, Vivienda y Desarrollo Territorial, Corporación Nacional de Investigación y Fomento Forestal- CONIF y Organización Internacional de Maderas Tropicales (OIMT); 335 p.

Villalba. J. C. 2008. Los manglares en el mundo y en Colombia: Estudio descriptico básico. Córdoba: Sociedad Geográfica de Colombia, Academia de Ciencias Geográficas; 22 p. 